\title{
NCI CTEP SDC AIDS-related Human Papillomavirus Sub-Category Terminology
}

National Cancer Institute

\section{Source}

National Cancer Institute. NCI CTEP SDC AIDS-related Human Papillomavirus Sub-

Category Terminology. NCI Thesaurus. Code C103032.

AIDS-related Human Papillomavirus is an $\mathrm{NCl}$ Cancer Therapeutic Evaluation Program

(CTEP) Simplified Disease Classification (SDC) category used to organize cancer-related disease coding that harmonizes with and supports reporting based on the global standard Medical Dictionary for Drug Regulatory Reporting (MedDRA) terminology. 